\title{
Metabolism of Cholesteryl Esters of Rat Very Low Density Lipoproteins
}

\author{
Ole Faergeman and Richard J. Havel \\ From the Cardiovascular Research Institute and Department of Medicine \\ University of California, San Francisco, California 94143
}

A B S T R A C T Rat very low density lipoproteins $(d<$ 1.006), biologically labeled in esterified and free cholesterol, were obtained from serum $6 \mathrm{~h}$ after intravenous injection of particulate $\left[{ }^{3} \mathrm{H}\right]$ cholesterol. When injected into recipient animals, the esterified cholesterol was cleared from plasma with a half-life of $5 \mathrm{~min}$. After $15 \mathrm{~min}, 71 \%$ of the injected esterified $\left[{ }^{3} \mathrm{H}\right]$ cholesterol had been taken up by the liver, where it was rapidly hydrolyzed. After $60 \mathrm{~min}$ only $3.3 \%$ of the amount injected had been transferred, via lipoproteins of intermediate density, to the low density lipoproteins of plasma ( $d$ 1.019-1.063). Both uptake in the liver and transfer to low density lipoproteins occurred without change of distribution of ${ }^{3} \mathrm{H}$ in the various cholesteryl esters.

${ }^{3} \mathrm{H}$ appearing in esterified cholesterol of high density lipoproteins $(d>1.063)$ was derived from esterification, presumably by lecithin: cholesterol acyltransferase, of simultaneously injected free $\left[{ }^{3} \mathrm{H}\right]$ cholesterol. Content of free $\left[{ }^{3} \mathrm{H}\right]$ cholesterol in the very low density lipoproteins used for injection could be reduced substantially by incubation with erythrocytes. This procedure, however, increased the rate of clearance of the lipoproteins after injection into recipient rats.

These studies show that hepatic removal is the major catabolic pathway for cholesteryl esters of rat very low density lipoproteins and that transfer to low density lipoproteins occurs to only a minor extent.

\section{INTRODUCTION}

Studies of the catabolism of the triglyceride-rich lipoproteins of plasma, chylomicrons (2-4) and very low

A preliminary report of this work has been published (1). Received for publication 12 November 1974 and in revised form 30 January 1975.

${ }^{1} \mathrm{Mj} \phi \mathrm{s}$, O. D., O. Faergeman, R. L. Hamilton, and R. J. Havel. In preparation. density lipoproteins ${ }^{1}$ (VLDL), ${ }^{2}$ have demonstrated removal of most of the triglycerides in extrahepatic tissues, presumably by the action of lipoprotein lipase, followed by hepatic removal of the cholesteryl esters. The catabolic sequence is complex, involving interchange of certain polypeptide subunits with high density lipoproteins (HDL) (5) and, at least in the case of VLDL, transfer of part of the B-apoprotein to low density lipoproteins (LDL) (6-10). LDL has been considered possibly the major product of the catabolism of triglyceride-rich lipoproteins. Its main protein and lipid components are $B$-apoprotein and cholesteryl esters. In the present studies, we have attempted to evaluate the manner and extent to which cholesteryl esters of rat VLDL are taken ut in the liver or transferred to LDL.

\section{METHODS}

Radiolabeled lipids. $\left[1,2-{ }^{3} \mathrm{H}\right]$ Cholesterol, $50 \mathrm{Ci} / \mathrm{mmol}$ (New England Nuclear, Boston, Mass.) was found to be more than $97 \%$ pure by thin-layer chromatography. $1-2 \mathrm{mCi}$ were added to $5 \mathrm{mg}$ unlabeled cholesterol (Fisher Scientific Co., Pittsburgh, Pa.), and $5 \mathrm{ml}$ of an aqueous suspension of the cholesterol in $0.9 \% \mathrm{NaCl}$ and $4 \%$ human albumin (The Cutter Laboratories, Berkeley, Calif.) was prepared essentially as described by Wurster and Zilversmit (11). More than $96 \%$ of the radioactivity in this suspension was precipitable by digitcnin. For experiments involving radiolabeled triglyceride, $15 \mu \mathrm{Ci}\left[1-{ }^{14} \mathrm{C}\right]$ palmitate, $17.9 \mathrm{mCi} / \mathrm{mmol}$ (ICN Pharmaceuticals Inc., Life Sciences Group, Cleveland, Ohio) was dispersed in aqueous $\mathrm{NaHCO}_{3}$ and complexed to albumin (12).

Preparation of radiolabeled VLDL. VLDL were obtained from male Sprague-Dawley rats weighing about 250 g. They were maintained on standard Purina rat chow (Ralston Purina Co., St. Louis, Mo.) or fed a fructoserich diet (13) (fructose $73 \%$, casein $20 \%$, corn oil $2 \%$, vitamins $3 \%$, and salt $2 \%$ ) for 3-7 days to stimulate hepatic

${ }^{2}$ Abbreviations used in this paper: DTNB, 5,5'-dithiobis2-nitrobenzoic acid; EDTA [ethylene dinitrilo]-tetracetic acid disodium salt; HDL, high density lipoprotein(s) ; LCAT, lecithin: cholesterol acyltransferase; LDL, low density lipoprotein(s); VLDL, very low density lipoprotein(s). 
production of VLDL. Preliminary experiments showed that maximal incorporation of label into cholesteryl esters of serum VLDL occurred about $6 \mathrm{~h}$ after injection of $\left[{ }^{3} \mathrm{H}\right]-$ cholesterol into the tail vein of an unanesthetized rat. A short-lived peak of incorporation into VLDL-triglyceride appeared $30 \mathrm{~min}$ after injection of $\left[{ }^{14} \mathrm{C}\right]$ palmitate. Accordingly, these time intervals were used to obtain appropriately labeled VLDL. The rats were not fed after the injections. They were bled from the abdominal aorta under diethyl ether anesthesia and the blood was allowed to clot for 30 min at room temperature. Serum, obtained from blood centrifuged at $900 \mathrm{~g}$ for $15 \mathrm{~min}$, was chilled and centrifuged at its own density for $16 \mathrm{~h}$ at $100,000 \mathrm{~g}$ at $10^{\circ} \mathrm{C}$ in the 40.3 rotor of a Beckman preparative ultracentrifuge (Beckman Instruments, Inc., Fullerton, Calif.). The supernatant $d<1.006$ lipoproteins were recovered by tube slicing and used for injection into recipient rats on the same day. For determination of the chemical composition of VLDL, separate portions of the $d<1.006$ lipoproteins were recentrifuged once under the same conditions.

Only about $30 \%$ of the labeled cholesterol in the VLDL obtained as described above was esterified. Initial experiments included, therefore, as did part of Goodman's work with chylomicrons (14), a procedure for reducing radioactivity in free cholesterol. Blood obtained from male Sprague-Dawley rats weighing about $400 \mathrm{~g}$ was mixed with EDTA, $1 \mathrm{mg} / \mathrm{ml}$, and centrifuged at $900 \mathrm{~g}$ for $15 \mathrm{~min}$ at $4^{\circ} \mathrm{C}$. The plasma and buffy coat were removed and the erythrocytes were washed three times with 4 vol of Tyrode's solution from which $\mathrm{CaCl}_{2}$ had been omitted. After storage overnight in the wash solution and a final centrifugation, the erythrocytes $(10 \mathrm{ml} / \mathrm{mg}$ VLDL protein) were mixed with the VLDL and modified Tyrode's solution to give a hematocrit of about $35 \%$. The mixture was incubated at $37^{\circ} \mathrm{C}$ for $6 \mathrm{~h}$ with gentle shaking. After sedimentation of the cells by centrifugation, VLDL were reisolated by ultracentrifugation, as described. Lipids of erythrocytes were extracted with 30 parts of chloroform: methanol, $2: 1 \mathrm{vol} / \mathrm{vol}$ (15). This procedure increased the ratio of esterified $\left[{ }^{3} \mathrm{H}\right]-$ cholesterol to free $\left[{ }^{3} \mathrm{H}\right]$ cholesterol by approximately 10 -fold without appreciably affecting the content of esterified $\left[{ }^{3} \mathrm{H}\right]-$ cholesterol. As described in the following section, it also modified the rate of VLDL removal from plasma. Accordingly, subsequent experiments did not include this step.

Injection of $V L D L$ into recipient animals. The rats had been maintained on standard Purina rat chow and weighed about $250 \mathrm{~g}$. Plasma triglyceride concentration was 0.80 (SD 0.32) $\mathrm{mg} / \mathrm{ml}$. Esterified cholesterol concentrations in $d<1.006$ and $d 1.019-1.063$ lipoproteins were 0.020 (SD 0.006 ) and $0.063(\mathrm{SD} 0.018) \mathrm{mg} / \mathrm{ml}$ plasma, respectively. At about noon the animals were placed in a restraining cage, and $0.5-1.0 \mathrm{ml}$ of VLDL, containing less than $0.7 \mathrm{mg}$ triglyceride, was injected into a tail vein. At selected intervals, they were anesthetized with diethyl ether and bled from the abdominal aorta. The blood was mixed with EDTA, $1 \mathrm{mg} / \mathrm{ml}$, chilled in ice, and centrifuged at $900 \mathrm{~g}$ for $20 \mathrm{~min}$ at $4^{\circ} \mathrm{C}$. Except as noted below, 0.1 volume of 0.02 M 5,5'-dithiobis-2-nitrobenzoic acid (DTNB) (Sigma Chemical Co., St. Louis, Mo.) was added to each sample of plasma to inhibit lecithin: cholesterol acyltransferase (LCAT) (16). The plasma fractions were kept between 0 and $4{ }^{\circ} \mathrm{C}$ until the lipids were extracted. Lipoprotein fractions of $d<1.006, d 1.006-1.019, d 1.019-1.063$, and $d>1.063$ were obtained (17) for analysis. The livers and, in one experiment, other organs were removed immediately after exsanguination, rinsed in saline, homogenized in a Waring blendor (Waring Products Div., Dynamics Corp. of Amer- ica, New Hartford, Conn.), and extracted for at least $24 \mathrm{~h}$ at room temperature in 25 parts alcohol:acetone, $1: 1 \mathrm{vol} /$ vol.

Analyses. Protein in lipoprotein fractions was measured as described by Lowry, Rosebrough, Farr, and Randall (18). For lipid analyses, a portion of lipoprotein solution was treated by a modified Folch, Lees, and Sloane Stanley procedure (19) and the lipids were separated by silicic acid column chromatography (20). Extracts of tissues were filtered through Whatman filter paper No. 1 and a portion of the filtrate containing less than $50 \mathrm{mg}$ lipid was evaporated to dryness under nitrogen, redissolved in $50 \mathrm{ml}$ chloroform: methanol, $25: 1 \mathrm{vol} / \mathrm{vol}$, and treated with $4 \mathrm{~g}$ freshly activated silicic acid (Mallinckrodt Chemical Works, St. Louis, Mo.) to absorb the bulk (about $99 \%$ ) of the phospholipids. Lipid classes were then separated as described above. Cholesterol (21), triglycerides (22), and phospholipids (23) were measured in appropriate fractions. ${ }^{3} \mathrm{H}$ was assayed by liquid scintillation spectrometry after the lipids were dissolved in toluene containing 2,5-diphenyloxazole and 1,4-bis [2-(5-phenyloxazolyl) ]-benzene. Correction for quenching, when necessary, was performed with an internal standard.

Argentation thin layer chromatography of cholesteryl esters (24) was performed with Adsorbosil containing 25\% AgNO: (Applied Sciences Labs, Inc., State College, Pa.). Methyl esters of fatty acids of cholesteryl esters were separated by gas-liquid chromatography on a $\frac{1}{8}$-in $\times 11$-ft column of $12 \%$ ethylene glycol succinate on Chromosorb W (Applied Sciences Labs, Inc.) at $185^{\circ} \mathrm{C}$ (25). Distribution in weight per cent was determined by multiplying peak height by retention time.

Column chromatography of intact lipoproteins on $2 \%$ Agarose gel was performed as described by Sata, Estrich, Wood, and Kinsell (26). Apolipoproteins, extracted by tetramethylurea, were separated by polyacrylamide gel electrophoresis (27), and the activator property of VLDLproteins for lipoprotein lipase was measured as described by Bier and Havel (28). Standard methods of statistical analysis were employed (29). Plasma volume was taken as $4.0 \%$ of body weight.

\section{RESULTS}

Analysis of VLDL prepared from donor rats. The composition of VLDL obtained from animals fed Purina rat chow or fructose-rich diet is presented in Table I. The nonpolar "core" constituents, triglycerides and cholesteryl esters, constituted about $78 \%$ of the particle volume $(30)$. This indicates an average particle

TABLE I

Composition of VLDL from Rats on Two Diets

\begin{tabular}{lcrc}
\hline & $\begin{array}{c}\text { Purina rat chow } \\
(n=5)\end{array}$ & $\begin{array}{c}\text { Fructose diet } \\
(n=11)\end{array}$ & $P^{*}$ \\
\hline Triglycerides & $70.9(3.9)_{+}^{\ddagger}$ & $69.6(3.6)$ & $>0.20$ \\
Cholesteryl esters & $3.1(0.6)$ & $5.6(1.7)$ & $<0.01$ \\
Free cholesterol & $2.8(0.6)$ & $3.0(0.4)$ & $>0.20$ \\
Phospholipids & $12.6(3.0)$ & $12.2(1.9)$ & $>0.20$ \\
Protein & $10.7(1.7)$ & $9.6(1.7)$ & $>0.20$ \\
\hline
\end{tabular}

* Unpaired $t$ test.

$\ddagger$ Weight percent, mean and SI). 
TABLE II

Composition of VLDL from Fructose-Fed Rats Separated by Chromatography on $2 \%$ Agarose Gel

\begin{tabular}{|c|c|c|c|c|}
\hline Fraction & 1 & 2 & 3 & 4 \\
\hline \multicolumn{5}{|l|}{ Composition, weight $\%$} \\
\hline Triglycerides & 76.9 & 70.3 & 66.2 & 62.9 \\
\hline Cholesteryl esters & 4.3 & 5.3 & 7.0 & 9.1 \\
\hline Free cholesterol & 2.6 & 3.0 & 3.6 & 4.3 \\
\hline Phospholipids & 10.3 & 14.1 & 14.5 & 13.4 \\
\hline Protein & 6.0 & 7.3 & 8.7 & 10.2 \\
\hline Mean particle diameter, $\AA^{*}$ & 750 & 650 & 530 & 500 \\
\hline $\begin{array}{l}\text { Distribution of cholesteryl } \\
\text { esters, weight } \%\end{array}$ & 9.7 & 25.5 & 38.6 & 26.3 \\
\hline $\begin{array}{l}\text { Specific activity of esterified } \\
\text { cholesterol, } \mathrm{cpm} / \mathrm{mg}\end{array}$ & 64,600 & 84,700 & 88,100 & 87,600 \\
\hline
\end{tabular}

* Estimated from chemical composition (30).

diameter of about $550 \AA$ (30). VLDL from the fructosefed animals contained significantly more cholesteryl esters. No consistent differences between the polyacrylamide gel patterns of the tetramethylurea-soluble apolipoprotein components of VLDL from rats on the two diets were observed.

VLDL from fructose-fed rats were separated by gel filtration through a $2 \%$ Agarose column (Table II). About $10 \%$ of the cholesteryl esters were recovered in the void volume, in particles about $750 \AA$ in diameter (fraction 1). The remainder were eluted in a broad second peak with an average particle diameter of about 550

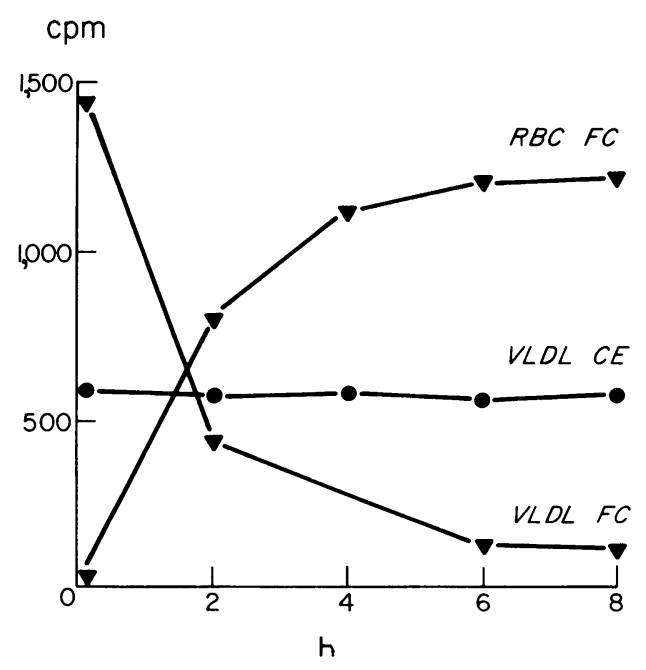

FIGURE 1 Effect of incubation of VLDL with erythrocytes. VLDL containing esterified (CE) and free (FC) $\left[{ }^{3} \mathrm{H}\right]-$ cholesterol were mixed with Tyrode's solution, from which $\mathrm{CaCl}_{\mathbf{2}}$ had been omitted, and unlabeled red blood cells (RBC), $10 \mathrm{ml}$ packed cells/mg VLDL-protein, to give a hematocrit of about $35 \%$. Incubation took place at $37^{\circ} \mathrm{C}$.
$\AA$ (fractions 2-4). The specific activity of esterified cholesterol was somewhat higher in fractions of the second peak than in the material eluted in the void volume.

The specific activity of different classes of cholesteryl esters separated by argentation thin layer chromatography was: saturated, $81 \%$; monounsaturated, $95 \%$; diunsaturated, 109\%; and tetraunsaturated, $138 \%$ of the value for unfractionated esters. (See Tables VII and VIII).

Effect of incubation of VLDL with erythrocytes. Equilibration of free cholesterol between VLDL and erythrocytes was nearly complete after $6 \mathrm{~h}$ (Fig. 1). The ratio of ${ }^{3} \mathrm{H}$ in esterified cholesterol to that in free cholesterol increased from 0.41 to 4.51 . Incubation with erythrocytes also modified the composition of VLDL (Table III). Content of free cholesterol increased significantly, indicating that net transfer of cholesterol from erythrocytes to VLDL also occurred. Content of phospholipids fell slightly. Polyacrylamide gel patterns of the tetramethylurea-soluble apolipoproteins were sim-

TABLE III

Effect of Incubation with Erythrocytes on the Composition of VLDL

\begin{tabular}{lcrl}
\hline & $\begin{array}{c}\text { Not incubated } \\
(n=4)\end{array}$ & $\begin{array}{c}\text { Incubated } \\
(n=4)\end{array}$ & $P^{*}$ \\
\hline Triglycerides & $67.6(2.2) \ddagger$ & $67.0(2.4)$ & \\
Cholesteryl esters & $6.3(1.2)$ & $5.8(1.2)$ & \\
Free cholesterol & $2.9(0.4)$ & $4.8(0.2)$ & $<0.01$ \\
Phospholipids & $12.3(2.4)$ & $11.3(2.7)$ & $<0.01$ \\
Protein & $10.9(3.4)$ & $11.2(4.9)$ & \\
\hline
\end{tabular}

* Paired $t$ test.

$\ddagger$ Weight percent; mean and SD. 
ilar (by densitometry, the three major bands accounted, in order of increasing mobility, for 18,35 , and $31 \%$ of the stained area before incubation, and 13,38 , and $34 \%$ after incubation with erythrocytes). Content of lipoprotein lipase activator was unchanged by incubation $\left(K_{m}=3.8 \mu \mathrm{g}\right.$ protein $/ \mathrm{ml}$ incubation medium).

When VLDL that had been incubated with erythrocytes were injected into recipient animals, the esterified $\left[{ }^{3} \mathrm{H}\right]$ cholesterol was removed rapidly from the plasma and taken up in the liver, as in the experiments with unincubated VLDL to be described below. However, this process took place more rapidly after incubation (Fig. 2). In another experiment, incubated and unincubated VLDL, labeled in both the cholesterol and triglyceride fatty acid moieties, were injected. 5 min after injection of incubated VLDL, hepatic cholesteryl esters contained $80 \%$ of the injected, esterified $\left[{ }^{3} \mathrm{H}\right]$ cholesterol and hepatic triglycerides contained $41 \%$ of the injected $\left[{ }^{14} \mathrm{C}\right]$ triglyceride fatty acid; corresponding values for unincubated VLDL were 44 and $24 \%$, respectively. Recovery of $\left[{ }^{14} \mathrm{C}\right]$ triglyceride in epididymal adipose tissue was threefold higher when unincubated VLDL were injected.

Fate of VLDL [ $\left.{ }^{3} H\right]$ cholestcrol. VLDL cholesteryl esters and free cholesterol were rapidly cleared from blood (Tables IV and V). Between 5 and 30 min after injection, the $t_{\frac{1}{2}}$ of esterified $\left[{ }^{3} \mathrm{H}\right]$ cholesterol in VLDL was about $5 \mathrm{~min}$ (Fig. 3). ${ }^{3} 15 \mathrm{~min}$ after injection, $71 \%$ of the injected esterified $\left[{ }^{3} \mathrm{H}\right]$ cholesterol was recovered in hepatic cholesteryl esters. This corresponds to $78 \%$ of the esterified $\left[{ }^{3} \mathrm{H}\right]$ cholesterol removed from plasma VLDL. The percent esterified hepatic $\left[{ }^{3} \mathrm{H}\right]$ cholesterol remained the same as that of the injected VLDL for at least $15 \mathrm{~min}$ (Table VI). By $60 \mathrm{~min}$, however, only about $6 \%$ of hepatic $\left[{ }^{3} \mathrm{H}\right]$ cholesterol was esterified.

Very little ${ }^{3} \mathrm{H}$ was recovered in either esterified or free cholesterol of lipoproteins of higher density. Very little radioactivity was found in esterified cholesterol of $d$ 1.006-1.019 lipoproteins (Table IV). In both $d 1.019$ 1.063 and $d>1.063$ lipoproteins, esterified $\left[{ }^{3} \mathrm{H}\right]$ cholesterol increased steadily to about $3 \%$ of the injected esterified $\left[{ }^{3} \mathrm{H}\right]$ cholesterol $60 \mathrm{~min}$ after injection. However, the distribution of radioactivity in the different cholesteryl esters, as determined by argentation thin layer chromatography, differed in these two lipopro-

\footnotetext{
${ }^{3}$ In a single experiment, labeled whole serum was injected into six rats; two were bled after 5,10 , and $15 \mathrm{~min}$. Samples of the donor serum and plasma from the recipients were fractionated and ${ }^{3} \mathrm{H}$ in VLDL cholesteryl esters was measured. The rate of removal of esterified $\left[{ }^{3} \mathrm{H}\right]$ cholesterol of VLDL was similar $\left(\mathrm{t}_{1}=4 \mathrm{~min}\right)$ to that observed when labeled VLDI, was injected. This suggests that the procedures used to prepare the VLDL did not affect their kinetic behavior in this respect, provided that they were not incubated with erythrocytes.
}

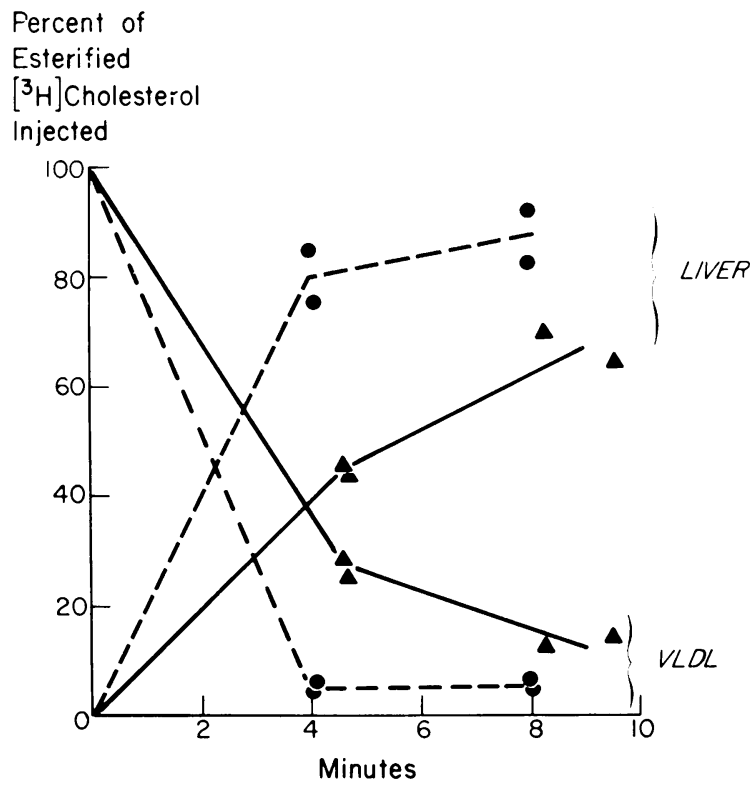

Figure 2 Effect of incubation with erythrocytes on VI.DL kinetics in vivo. VLDL incubated or not incubated with erythrocytes were injected into the tail veins of eight rats, which were anaesthetized and bled at the times indicated. Instantaneous mixing in a plasma volume of $4.0 \%$ of body weight was assumed. Esterified $\left[{ }^{3} \mathrm{H}\right]$ cholesterol in plasma VLDL and liver after injection of incubated VLDL (dashed lines) and unincubated VLDL (solid lines).

tein classes (Table VII). In the esters of the $d$ 1.0191.063 lipoproteins, as well as in hepatic cholesteryl esters, the distribution closely resembled that of the VLDL injected. The dominant fatty acid was monounsaturated. In the $d>1.063$ lipoproteins, most of the radioactivity was in cholesterol esterified with tetraunsaturated acid.

Content of individual fatty acids of cholesteryl esters in both $d<1.006$ lipoproteins from donor animals and in $d>1.063$ lipoproteins from recipient animals corresponded to the distribution of esterified $\left[{ }^{3} \mathrm{H}\right]$ cholesterol (Table VIII). By contrast, the fatty acid content of cholesteryl esters in the $d$ 1.019-1.063 lipoproteins more nearly resembled that of $d>1.063$ lipoproteins, whereas the distribution of esterified $\left[{ }^{3} \mathrm{H}\right]$ cholesterol, as noted above, closely reflected the distribution of radioactivity in the injected VLDL.

To determine whether this result reflected the presence of HDL-like particles in the $d 1.019-1.063$ fraction, the fatty acid content of cholesteryl esters was determined in subfractions of $d 1.019-1.045$ and 1.045-1.063. Each subfraction contained $4-5 \%$ of the cholesteryl esters present in whole plasma. The $d 1.019-1.045$ fraction contained primarily $\beta$-lipoprotein. as determined by electrophoresis on Agarose gel, with a very small amount of material that migrated in the $\alpha$-globulin region, whereas the $d$ 1.045-1.063 fraction contained 
TABLE IV

Esterified $\left[{ }^{3} \mathrm{H}\right]$ Cholesterol as Percentage of Injected VLDL Esterified $\left[{ }^{3} \mathrm{H}\right]$ Cholesterol

\begin{tabular}{cccccc}
\hline \multirow{5}{*}{$\begin{array}{c}\text { Time } \\
\text { after } \\
\text { injection }\end{array}$} & $\begin{array}{c}d<1.006 \\
(n=8)\end{array}$ & $\begin{array}{c}d 1.006-1.019 \\
(n=8)\end{array}$ & $\begin{array}{c}d 1.019-1.063 \\
(n=8)\end{array}$ & $\begin{array}{c}d>1.063 \\
(n=6)\end{array}$ & $\begin{array}{c}\text { Liver } \\
(n=8)\end{array}$ \\
\hline $\min$ & & & & & \\
5 & $37.9(12.3)^{*}$ & $2.2(1.1)$ & $1.2(0.7)$ & $1.3(0.3)$ & $50.8(12.9)$ \\
10 & $20.2 \ddagger$ & 1.9 & 1.5 & 1.5 & 64.5 \\
15 & $8.8(6.8)$ & $2.5(1.3)$ & $1.6(1.2)$ & $1.4(0.3)$ & $70.9(10.2)$ \\
30 & $1.5(0.9)$ & $2.1(1.6)$ & $2.3(1.7)$ & $1.7(0.5)$ & $31.2(8.8)$ \\
60 & $1.6(0.5)$ & $1.4(0.9)$ & $3.3(1.8)$ & $3.2(1.2)$ & $12.4(2.4)$ \\
\hline
\end{tabular}

* Mean and SD values calculated for plasma volume $=4 \%$ of body wt.

$\ddagger n=2$.

roughly equal amounts of $\beta$ and $\alpha$ lipoproteins. Cholesteryl esters of the $d 1.019-1.045$ fraction also resembled those of the $d>1.063$ fraction more closely than those of $d<1.006$ lipoproteins (Table VIII), indicating that the mass and ${ }^{3} \mathrm{H}$ distributions differed in $\beta$-migrating LDL.

In one experiment no DTNB was added to the plasma from the recipient animals. However, data from this experiment (exp. A in Table VII) pertaining to $d>1.063$ lipoproteins were not included in Tables IV and $\mathrm{V}$ on the basis of the following control experiment: $d<1.063$ and $d>1.063$ lipoproteins from recipient animals were separated by centrifugation for $6 \mathrm{~h}$ at $100,000 \mathrm{~g}$ immediately and after storage for $72 \mathrm{~h}$ at $4^{\circ} \mathrm{C}$. Esterified $\left[{ }^{3} \mathrm{H}\right]$ cholesterol in the $d>1.063$ lipoproteins increased by $90 \%$ during storage. In the $d<1.063$ fraction, the increase was only $7 \%$. Thus, maintaining plasma samples at temperatures as low as $4^{\circ} \mathrm{C}$ failed, in the absence of an inhibitor of LCAT, to prevent appreciable esterification of cholesterol in $d>1.063$ lipoproteins.

\section{DISCUSSION}

The present studies show that most cholesteryl esters of rat VLDL are rapidly removed from plasma by the liver, and suggest that during this process only a very small fraction is first transferred to plasma lipoproteins of higher density. The half-life of VLDL cholesteryl esters in plasma was about $5 \mathrm{~min}$. At least $78 \%$ of the esters removed from VLDL 15 min after injection had been taken up in the liver. For at least $15 \mathrm{~min}$ after injection, little hydrolysis of these esters in the liver was evident; the percentage of $\left[{ }^{3} \mathrm{H}\right]$ cholesterol esterified remained closely similar to that of the injected VLDL. After 30 and $60 \mathrm{~min}$, respectively, $58 \%$ and $80 \%$ of the esters had been hydrolyzed.

These results are similar to those obtained in studies of chylomicron cholesteryl esters, which indicated uptake of intact esters by hepatocytes and subsequent hydrolysis in the region of the plasma membrane (14, $31,32)$. However, both the rate of removal of the esters from the plasma and the rate of their hydrolysis in the liver were somewhat higher in our VLDL studies. This is unlikely to reflect physiological differences in metabolism, since large triglyceride-rich particles are more rapidly metabolized than small ones under the same experimental conditions (31). Rather, it probably reflects differences in the amount of lipoprotein injected (32). Per rat we injected less than $0.7 \mathrm{mg}$ VLDL-tri-

TABLE V

Free $\left[{ }^{3} \mathrm{H}\right]$ Cholesterol as Percent of Injected VLDL Free $\left[{ }^{3} \mathrm{H}\right]$ Cholesterol

\begin{tabular}{cccccc}
\hline \multirow{5}{*}{$\begin{array}{c}\text { Time } \\
\text { after } \\
\text { injection }\end{array}$} & $\begin{array}{c}d<1.006 \\
(n=8)\end{array}$ & $\begin{array}{c}d 1.006-1.019 \\
(n=8)\end{array}$ & $\begin{array}{c}d 1.019-1.063 \\
(n=8)\end{array}$ & $\begin{array}{c}d>1.063 \\
(n=6)\end{array}$ & $\begin{array}{c}\text { Liver } \\
(n=8)\end{array}$ \\
\cline { 2 - 5 } min & & & & & \\
5 & $26.7(10.7)^{*}$ & $1.4(0.8)$ & $4.1(1.1)$ & $6.9(0.8)$ & $53.5(7.5)$ \\
10 & $13.7 \ddagger$ & 1.1 & 3.4 & 4.9 & 59.9 \\
15 & $4.4(3.8)$ & $0.9(0.5)$ & $1.9(0.5)$ & $2.9(0.8)$ & $74.2(9.9)$ \\
30 & $0.9(0.4)$ & $0.6(0.4)$ & $1.6(0.4)$ & $2.3(0.3)$ & $91.9(14.0)$ \\
60 & $1.5(0.6)$ & $0.6(0.4)$ & $1.8(0.7)$ & $3.5(0.4)$ & $82.0(8.3)$ \\
\hline
\end{tabular}

* Mean and SD values calculated for plasma volume $=4 \%$ of body wt. $\ddagger n=2$. 
glyceride, which corresponds to less than $10 \%$ of the triglycerides circulating in the plasma of these animals. In the cited studies with chylomicrons, from 20 to 50 times as much lipoprotein-lipid was injected. When smaller amounts of chylomicrons are injected into unanesthetized rats, the half-life of component triglycerides is about $3 \mathrm{~min}$ and, as with our VLDL, a minor fraction appears in hepatic triglycerides (33).

Of the esterified $\left[{ }^{3} \mathrm{H}\right]$ cholesterol removed from plasma VLDL after $60 \mathrm{~min}$, only $3.4 \%$ was found in LDL (d 1.019-1.063). The distribution of label in the various esters of LDL was identical to that of the VLDL esters injected and the esters taken up by the liver. In functionally hepatectomized rats, "remnant" particles depleted of triglycerides but retaining component cholesteryl esters are formed from $\operatorname{VLDL}(34,35)$ as well as from chylomicrons $(3,34)$. In intact rats, most of these particles, while still in the very low density $(<1.006)$ or intermediate density $(1.006-1.019)$ range, evidently leave the circulation in the liver with their full complement of cholesteryl esters, but only a minority of the triglycerides originally present. A small fraction, however, which recent studies have shown to be larger in the guinea pig," loses enough triglyceride to be isolated. with its complement of cholesterol esters, in the $d$ 1.019-1.063 range as LDL. Whether the cholesteryl esters that appear in LDL are initially taken up by the liver and subsequently released into the blood is uncertain. The fraction of VLDL that completes the conversion to LDL may be much larger in man. In this context it may be noted that only a small fraction of apolipoprotein $\mathrm{B}$ is transferred to LDL during catabolism of VLDL in the rat $(9,10,36)$, in contrast to the human, where as much as $10-25 \%(6,8)$ of injected VLDL apolipoproteins may be recovered in LDL after $24 \mathrm{~h}$.

With a plasma volume of about $12 \mathrm{ml}$, the pools of

${ }^{4}$ Barter, P. J., O. Faergeman, and R. J. Havel. Unpublished data.

\section{Percent of \\ Esterified \\ $\left[{ }^{3} \mathrm{H}\right]$ Cholesterol \\ Injected}

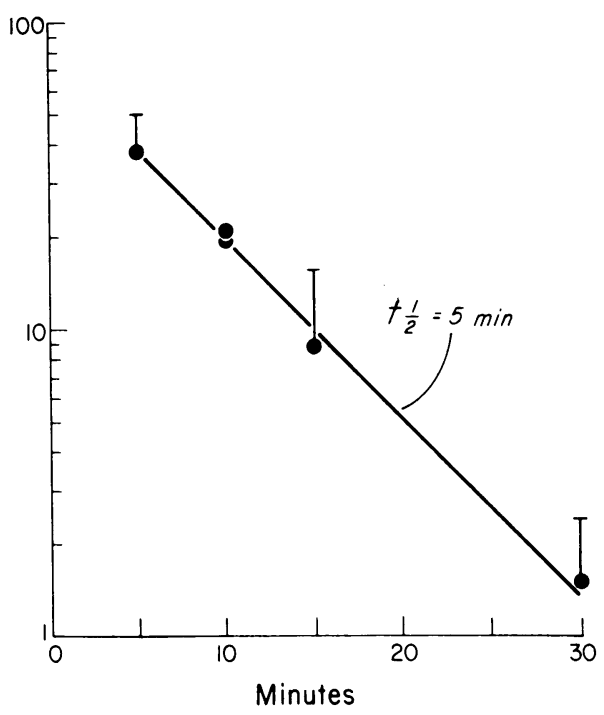

Figure 3 Removal of VLDI, esterified $\left[{ }^{3} \mathrm{H}\right]$ cholesterol from plasma. Semilogarithmic plot of data in Table IV. Mean and SD.

plasma cholesteryl esters in VLDL and LDL of our recipient animals were about $0.24 \mathrm{mg}$ and $0.76 \mathrm{mg}$, respectively. The half-life of plasma VLDL cholesteryl esters was $5 \mathrm{~min}$. If cholesteryl esters of LDL turn over at the same rate as the protein moiety, the half-life of LDL cholesteryl esters is between $1 \frac{1}{2}$ (9) and $7 \mathrm{~h}$ (37). Based on these figures, VLDL cholesteryl esters leave plasma at a rate of $2.0 \mathrm{mg} / \mathrm{h}$, whereas the rate for LDL cholesteryl esters is between 0.35 and 0.08 $\mathrm{mg} / \mathrm{h}$. Thus, if all LDL cholesteryl esters were derived from VLDL, between $18 \%$ and $4 \%$ of VLDL cholesteryl esters would be expected to transfer to LDL. That this is unlikely is suggested by the gas chromatographic

TABLE VI

Recoiery of Injected $\left[{ }^{3} \mathrm{H}\right]$ Cholesterol in Liver

\begin{tabular}{ccccc}
\hline $\begin{array}{c}\text { Time } \\
\text { Tifter } \\
\text { injection }\end{array}$ & $n$ & \multicolumn{2}{c}{ Distribution of $\left[{ }^{3} \mathrm{H}\right]$ cholesterol in liver } & $\begin{array}{c}{\left[{ }^{3} \mathrm{H}\right] \text { Cholesterol* }} \\
\text { present as } \\
\text { esters }\end{array}$ \\
\cline { 3 - 4 } $\min$ & & Cholesteryl esters & Free cholesterol & $\%$ \\
5 & 8 & $14.4(1.7) \ddagger$ & $38.0(7.9)$ & 27.5 \\
10 & 2 & 17.2 & 44.7 & 27.7 \\
15 & 8 & $20.7(3.3)$ & $52.1(6.9)$ & 28.4 \\
30 & 8 & $9.2(3.1)$ & $64.2(4.5)$ & 12.5 \\
60 & 8 & $3.6(0.7)$ & $57.4(2.9)$ & 5.9 \\
\hline
\end{tabular}

* Percent esterified $\left[{ }^{3} \mathrm{H}\right]$ cholesterol in injected VLDL $=29.6(6.8)$.

$\ddagger$ Mean and SD. 
TABLE VII

Percent Distribution of Radioactivity in Cholesteryl Esters with Varying Unsaturation of the Fatty Acid Moiety

\begin{tabular}{|c|c|c|c|c|c|c|}
\hline \multirow{2}{*}{$\begin{array}{l}\text { Experi- } \\
\text { ment }\end{array}$} & \multirow[b]{2}{*}{ Sample } & \multirow{2}{*}{$\begin{array}{c}\text { Time } \\
\text { after } \\
\text { injection }\end{array}$} & \multicolumn{4}{|c|}{ Unsaturated bonds } \\
\hline & & & 0 & 1 & 2 & 4 \\
\hline & & $\min$ & & & & \\
\hline \multicolumn{7}{|c|}{ Donor rat } \\
\hline $\mathrm{A}$ & $d<1.006$ & & 18 & 41 & 20 & 21 \\
\hline B & & & 18 & 43 & 26 & 14 \\
\hline \multicolumn{7}{|c|}{ Recipient rat } \\
\hline A & liver & 15 & 18 & 41 & 21 & 19 \\
\hline A & & 60 & 22 & 43 & 21 & 13 \\
\hline A & $d 1.019-1.063$ & 60 & 17 & 40 & 22 & 22 \\
\hline B & & 60 & 19 & 50 & 19 & 12 \\
\hline A & $d>1.063$ & 60 & 7 & 6 & 20 & 68 \\
\hline B & & 60 & 10 & 14 & 22 & 55 \\
\hline
\end{tabular}

* DTNB added to plasma immediately after separation from cells (final concentration, $2 \mathrm{mM}$ ) in exp. B only.

data in Table VIII. The fatty acid composition of cholesteryl esters of $d$ 1.019-1.063 lipoproteins is intermediate between that of $d<1.006$ and $d>1.063$ lipoproteins, in agreement with earlier findings (38); our data show further that this composition applies to the $\beta$-lipoprotein in the LDL density range. A substantial portion of cholesteryl esters of $\beta$-lipoprotein of the rat are, therefore, probably produced by LCAT. This enzyme is evidently responsible for the $\left[{ }^{3} \mathrm{H}\right]$ cholesterol that progressively appeared in the mainly tetraunsaturated esters of HDL after injection of labeled VLDL (Tables IV and VII).

Both 15 and 60 min after injection of VLDL, the pattern of esterification of hepatic $\left[{ }^{3} \mathrm{H}\right]$ cholesterol was virtually identical to that of the injected VLDL (Table VII). Although the fatty acid composition of hepatic cholesteryl esters also resembles that of VLDL (38), very little hepatic esterification of free $\left[{ }^{3} \mathrm{H}\right]$ cholesterol is likely to have taken place at these time intervals (31). We also found little evidence for hydrolysis of cholesteryl ester $15 \mathrm{~min}$ after injection of VLDL ( Table VI). The various cholesteryl esters of VLDL are, therefore, probably removed from plasma and hydrolyzed in the liver at about the same rate. In experiments in which labeled mevalonate was injected into rats, Gidez, Roheim, and Eder (39) found that label was most rapidly incorporated into monounsaturated cholesteryl esters of $d<1.019$ lipoproteins and most slowly into the tetraunsaturated esters, with saturated and diunsaturated esters intermediate. The system they studied was complex, however, involving cholesterol synthesis and esterification as well as incorporation of cholesteryl esters into lipoproteins. It is likely that different rates of cholesterol esterification in the liver (40) or transfer of small amounts of labeled esters from HDL determined the differences in the rates of appearance of label in $d<1.019$ lipoproteins of plasma, rather than different turnover rates once the cholesteryl esters had been incorporated into these lipoproteins.

The labeled VLDL we employed for injection into recipient rats were presumably mainly of hepatic origin. When particulate cholesterol is injected intravenously into rats, the major part is quickly taken up by the liver's Kupffer cells, from which it is subsequently released to a pool of exchangeable free cholesterol (41). As such, it is available for esterification in the liver, the major site of VLDL synthesis. The intestine plays a smaller but significant role in production of VLDL (42), but intestinal VLDL-cholesterol in the rat is mainly derived from the intestinal lumen (43). Hepatic synthesis of cholesteryl esters that are then returned to the liver and hydrolyzed constitutes an apparently

TABLE VIII

Percent Fatty Acid Distribution in Cholesteryl Esters Determined by Gas Liquid Chromatography

\begin{tabular}{cccccc}
\hline Fatty acid & $\begin{array}{c}d<1.006 \\
(n=4)\end{array}$ & $\begin{array}{c}d .019-1.063 \\
(n=1)\end{array}$ & $\begin{array}{c}d .019-1.045 \\
(n=2)\end{array}$ & $\begin{array}{c}d .045-1.063 \\
(n=2)\end{array}$ & $\begin{array}{c}d>1.063 \ddagger \\
(n=3)\end{array}$ \\
\hline $14: 0$ & $1.1(1.0)^{*}$ & 0.4 & 0.3 & 0.5 & $0.2(0.06)$ \\
$14: 1$ & $0.5(0.3)$ & 0.3 & 0.5 & - & 0.2 \\
$16: 0$ & $16.4(4.9)$ & 9.4 & 11.4 & 11.0 & $5.3(0.2)$ \\
$16: 1$ & $9.4(5.9)$ & 1.9 & 2.7 & 2.3 & $2.0(2.1)$ \\
$18: 0$ & $4.8(2.1)$ & 1.1 & 1.1 & 1.6 & $0.8(0.5)$ \\
$18: 1$ & $34.4(10.5)$ & 8.7 & 11.2 & 6.5 & $4.8(2.5)$ \\
$18: 2$ & $21.1(9.5)$ & 27.1 & 31.6 & 28.6 & $19.2(1.5)$ \\
$20: 4$ & $12.4(7.0)$ & 51.1 & 40.6 & 49.4 & $67.5(3.3)$
\end{tabular}

* Mean and SI).

$\ddagger$ The size of the 18:2 and especially the 20:4 peaks was reduced in cholesteryl esters from undialyzed $d>1.063$ lipoproteins, and a broader peak, with longer retention time than the 20:4 methyl ester, was present. This effect of DTNB was reversed by dialysis of the DTNB-treated lipoprotein. 
fruitless cycle. If these esters have a role in VLDL synthesis, it is obscure. They may also be important for the catabolism of other remnant components.

Our preparation of VLDL for injection contained $\left[{ }^{3} \mathrm{H}\right]$ cholesterol mainly in unesterified form. We utilized the well-known in vitro exchange of free cholesterol between lipoproteins and erythrocytes to reduce free $\left[{ }^{3} \mathrm{H}\right]$ cholesterol in VLDL while maintaining the content of esterified $\left[{ }^{3} \mathrm{H}\right]$ cholesterol. The incubation procedure, however, modified the VLDL so that, when injected into recipient rats, they were removed from the blood much more rapidly by the liver. Since these VLDL had acquired free cholesterol and lost phospholipids, both surface components of the lipoprotein (30), it is possible that their "recognition" by the liver was altered, with premature removal from the circulation as a result. Free cholesterol of unincubated VLDL was also rapidly and extensively taken up by the liver, although more was recovered in $d>1.006$ lipoproteins, presumably because of molecular exchange. The extensive hepatic uptake of both surface and core components of presumed VLDL remnants suggests that the particle may be taken up intact before its components are further metabolized.

\section{ACKNOWLEDGMENTS}

We are grateful to Agnes Frank, Leila Kotite, and Tsunako Sata for their expert technical assistance.

Dr. Faergeman was the recipient of a Public Health Service International Research Fellowship (no. F05 TW 1939) and of stipends from the Danish Heart Association and the Danish Medical Research Council. This work was supported by a grant from the U. S. Public Health Service (HL 06285).

\section{REFERENCES}

1. Faergeman, O., O. D. Mjøs, and R. J. Havel. 1974. Metabolism of cholesteryl esters of rat very low density lipoproteins. Clin. Res. 22: 128a. (Abstr.)

2. Nestel, P. J., R. J. Havel, and A. Bezman. 1963. Metabolism of constituent lipids of dog chylomicrons. J. Clin. Invest. 42: 1313-1321.

3. Redgrave, T. G. 1970. Formation of cholesteryl esterrich particulate lipid during metabolism of chylomicrons. J. Clin. Invest. 49: 465-471.

4. Bergman, E. N., R. J. Havel, B. M. Wolfe, and T. B $\varnothing$ hmer. 1971. Quantitative studies of the metabolism of chylomicron triglycerides and cholesterol by liver and extrahepatic tissues of sheep and dogs. J. Clin. Invest. 50: 1831-1839.

5. Havel, R. J. 1972. Mechanisms of hyperlipoproteinemia. In Pharmacological Control of Lipid Metabolism. W L. Holmes, R. Paoletti, and D. Kritchevsky, editors. Plenum Publishing Corporation, New York. 57-70.

6. Gitlin, D., D. G. Cornwell, D. Nakasato, J. L. Oncley, W. L. Hughes, Jr., and C. A. Janeway. 1958. Studies on the metabolism of plasma proteins in the nephrotic syndrome. II. The lipoproteins. J. Clin. Ini'st. 37: 172184.

7. Fidge, N. H., and C. J. Foxman. 1971. In vivo transformation of rat plasma very low density lipoprotein into higher density lipoproteins. Aust. J. Exp. Biol. Med. Sci. 49: 581-593.

8. Bilheimer, D. W., S. Eisenberg, and R. I. Levy. 1972. The metabolism of very low density lipoproteins proteins. Biochim. Biophys. Acta. 260:212-221.

9. Eisenberg, S., and D. Rachmilewitz. 1973. Metabolism of rat plasma very low density lipoprotein. I. Fate in circulation of the whole lipoprotein. Biochim. Biophys. Acta. 326: 378-390.

10. Faergeman, O., T. Sata, J. P. Kane, and R. J. Havel. 1974. Metabolism of apo-lipoprotein B of plasma very low density lipoproteins in the rat. Circulation. 50 (Suppl. III) : 114. (Abstr.)

11. Wurster, N. B., and D. B. Zilversmit. 1971. The role of phagocytosis in the development of atherosclerotic lesions in the rabbit. Atherosclerosis. 14: 309-322.

12. Fredrickson, D. S., and R. S. Gordon, Jr. 1958. The metabolism of albumin-bound $\mathrm{C}^{14}$-labeled unesterified fatty acids in normal human subjects. J. Clin. Invest. 37: 1504-1515.

13. Zakim, D., R. S. Pardini, R. H. Herman, and H. E. Sauberlich. 1967. Mechanism for the differential effects of high carbohydrate diets on lipogenesis in rat liver. Biochim. Biophy's. Acta. 144: 242-251.

14. Goodman, D. S. 1962. The metabolism of chylomicron cholesterol ester in the rat. J. Clin. Invest. 41: 18861896.

15. Nelson, G. J. 1972. Handling, extraction, and storage of blood samples. In Blood Lipids and Lipoproteins: Quantitation, Composition, and Metabolism. G. J. Nelson, editor. John Wiley \& Sons, Inc., New York. 3-24.

16. Stokke, K. T., and K. R. Norum. 1971. Determination of lecithin:cholesterol acyltransferase in human blood plasma. Scand. J. Clin. Lab. Invest. $27: 21-27$.

17. Havel, R. J., H. A. Eder, and J. H. Bragdon. 1955. The distribution and chemical composition of ultracentrifugally separated lipoproteins in human serum. $J$. Clin. Invest. 34 : 1345-1353.

18. Lowry, O. H., N. J. Rosebrough, A. L. Farr, and R. J. Randall. 1951. Protein measurement with the Folin phenol reagent. J. Biol. Chem. 193: 265-275.

19. Folch, J., M. Lees, and G. H. Sloane Stanley. 1957. A simple method for the isolation and purification of total lipids from animal tissues. J. Biol. Chem. 226: 497-509.

20. Havel, R. J., J. M. Felts, and C. M. Van Duyne. 1962 Formation and fate of endogenous triglycerides in blood plasma of rabbits. J. Lipid Res. 3: 297-308.

21. Sperry, W. M., and M. Webb. 1950. A revision of the Schoenheimer-Sperry method for cholesterol determination. J. Biol. Chem. 187: 97-106.

22. Carlson, L. A. 1963. Determination of serum triglycerides. J. Atheroscler. Res. 3: 334-336.

23. Stewart, C. P., and E. B. Hendry. 1935. The phospholipins of blood. Biochem. J. 29: 1683-1689.

24. Goodman, D. S., and T. Shiratori. 1964. In vivo turnover of different cholesterol esters in rat liver and plasma. J. Lipid Res. 5 : 578-586.

25. King, R. J., and J. A. Clements. 1970. Separation by gel chromatography of naturally occurring phosphatidylcholine mixtures according to number of ethylenic linkages. J. Lipid Res. $11:$ 381-385.

26. Sata, T., D. L. Estrich, P. D. S. Wood, and L. W. Kinsell. 1970. Evaluation of gel chromatography for plasma lipoprotein fractionation. J. Lipid Rcs. 11:331340. 
27. Kane, J. P. 1973. A rapid electrophoretic technique for identification of subunit species of apoproteins in serum lipoproteins. Anal. Biochem. 53: 350-364.

28. Bier, D. M., and R. J. Havel. 1970. Activation of lipoprotein lipase by lipoprotein fractions of human serum. J. Lipid Res. 11: 565-570.

29. Snedecor, G. W., and W. G. Cochran. 1967. Statistical Methods. The Iowa State University Press, Ames, Iowa. 6th edition.

30. Sata, T., R. J. Havel, and A. L. Jones. 1972. Characterization of subfractions of triglyceride-rich lipoproteins separated by gel chromatography from blood plasma of normolipemic and hyperlipemic humans. $J$. Lipid Res. 13: 757-768.

31. Quarfordt, S. H., and D. S. Goodman. 1967. Metabolism of doubly-labeled chylomicron cholesteryl esters in the rat. J. Lipid Res. 8: 264-273.

32. Stein, O., Y. Stein, D. S. Goodman, and N. H. Fidge. 1969. The metabolism of chylomicron cholesteryl ester in rat liver. J. Cell Biol. 43: 410-431.

33. Jones, N. L., and R. J. Havel. 1967. Metabolism of free fatty acids and chylomicron triglycerides during exercise in rats. Am. J. Physiol. 213: 824-828.

34. Mjøs, O. D., O. Faergeman, R. L. Hamilton, and R. J. Havel. 1974. Characterization of "remnants" of lymph chylomicrons and lymph and plasma very low density lipoproteins in "supradiaphragmatic" rats. Eur. J. Clin. Invest. 4: 382-383. (Abstr.)

35. Fielding, C. J., and J. M. Higgins. 1974. Mechanism of formation of triglyceride-rich remnant particles from very low density lipoproteins in the perfused rat heart. Fed. Proc. 33 : 351. (Abstr.)

36. Roheim, P. S., D. I. Edelstein, G. Vega, and H. A. Eder. 1973. Metabolism of very low density apolipoproteins in sucrose-fed hyperlipemic rats. Fed. Proc. 32: 672. (Abstr.)

37. Roheim, P. S., H. Hirsch, D. Edelstein, and D. Rachmilewitz. 1972. Metabolism of iodinated high density lipoprotein subunits in the rat. Biochim. Biophys. Acta. 278: $517-529$.

38. Gidez, L. I., P. S. Roheim, and H. A. Eder. 1965. Effect of diet on the cholesterol ester composition of liver and of plasma lipoproteins in the rat. J. Lipid Res. $6: 377-382$.

39. Gidez, L. I., P. S. Roheim, and H. A. Eder. 1967. Turnover of cholesteryl esters of plasma lipoproteins in the rat. J. Lipid Res. 8: 7-15.

40. Goodman, D. S., D. Deykin, and T. Shiratori. 1964. The formation of cholesterol esters with rat liver enzymes. J. Biol. Chem. 239: 1335-1345.

41. Nilsson, A., and D. B. Zilversmit. 1972. Fate of intravenously administered particulate and lipoprotein cholesterol in the rat. J. Lipid Res. 13: 32-38.

42. Cenedella, R. J., W. G. Crouthamel, and H. F. Mengoli. 1974. Intestinal versus hepatic contribution to circulating triglyceride levels. Lipids. 9: 35-42.

43. Ockner, R. K., F. B. Hughes, and K. J. Isselbacher. 1969. Very low density lipoproteins in intestinal lymph: origin, composition, and role in lipid transport in the fasting state. J. Clin. Invest. 48: 2079-2088. 